\title{
Electron beam immobilization of functionalized poly(vinyl methyl ether) thin films on polymer surfaces - Towards stimuli responsive coatings for biomedical purposes
}

\author{
S. Gramm ${ }^{1,2 *}$,J. Teichmann ${ }^{1,2,3}$, M. Nitschke ${ }^{1,2}$, U. Gohs ${ }^{1}$, K.-J. Eichhorn ${ }^{1}$, C. Werner ${ }^{1,2,4}$ \\ ${ }^{1}$ Leibniz Institute of Polymer Research Dresden, Hohe Str. 6, 01069 Dresden, Germany \\ ${ }^{2}$ Max Bergmann Center of Biomaterials Dresden, Budapester Str. 27, 01069 Dresden, Germany \\ ${ }^{3}$ University Hospital Dresden Carl Gustav Carus, Anatomy, Fetscherstr. 74, 01307 Dresden, Germany \\ ${ }^{4}$ Center for Regenerative Therapies Dresden, Tatzberg 47, 01187 Dresden, Germany
}

\begin{abstract}
Thin films of poly(vinyl methyl ether) (PVME) were immobilized on polystyrene surfaces by low energy electron beam cross-linking. Structure retention as well as the thermo-responsive swelling behavior in aqueous media were studied by attenuated total reflection Fourier transform infrared spectroscopy (ATR-FTIR) and spectroscopic ellipsometry respectively. The physical properties of the thermo-responsive coatings can be controlled in a wide range by adjusting the irradiation parameters. To allow for a variety of biomolecular functionalization strategies, the concept was extended by adding reactive sites to the system. For that purpose a mixture of PVME and the copolymer of PVME and maleic acid was applied, that possesses a similar stimuli-responsive behavior.
\end{abstract}

Keywords: polymer gels, stimuli responsive polymers, poly(vinyl methyl ether), maleic anhydride, low energy electrons

\section{Introduction}

Stimuli responsive polymers (SRP) are materials that exhibit dramatic changes of their properties upon slight changes in the environmental conditions $[1,2]$. For biomedical purposes surface-immobilized SRP films with a thermally stimulated phase transition close to the physiological range are of particular interest [3]. When immersed in aqueous media, the abrupt change in solubility at the lower critical solution temperature (LCST) leads to a reversible swelling and collapsing of the immobilized film upon small temperature changes [4]. To meet the specific requirements for sophisticated applications like the control of cell surface adhesion, there is a strong need to fine-tune the physicochemical properties of the SRP coating [5, 6]. While the most popular thermo-responsive material for this purpose is poly $(\mathrm{N}$ isopropylacrylamide) $(\mathrm{PNi}-$ PAAm, $\left.\operatorname{LCST}=32^{\circ} \mathrm{C}\right)[7,8]$, the approach reported here is based on poly(vinyl methyl ether) (PVME, $\left.\mathrm{LCST}=34^{\circ} \mathrm{C}\right)[9,10]$. The distinct thermo-responsive behavior with a LCST only a few Kelvin below the standard cell cultivation temperature predestines PVME as a coating for thermo-responsive cell culture carriers. However, there are only few studies on the application of polyvinylether based hydrogels for this purpose [11]. Contrary to PNiPAAm, PVME possesses a high affinity to electron beam cross-linking $[12,13]$. This allows to immobilize PVME films on polymeric substrates like polystyrene with a defined thickness and swelling behavior in wide range.

Beyond that, the functional modulation of a thermoresponsive coating with bioactive molecules can

\footnotetext{
${ }^{*}$ Corresponding author, e-mail: gramm@ipfdd.de
}

(c) BME-PT 
further improve the performance. Hatakeyama et al. demonstrate the promotion of cell adhesion and proliferation on thin PNiPAAm films by the immobilization of cell adhesive peptides and growth factors [14]. On the other hand, Kwon et al. [15] show the acceleration of cell detachment from PNiPAAmbased cell culture carriers by the introduction of poly(ethylene glycol) chains. Altogether, these strategies allow to adjust initial adhesion and detachment properties for a particular type of cell culture. Towards this goal, PVME-based thermo-responsive coatings can be chemically functionalized by crosslinking as a mixture with other (co)polymers. In particular, the introduction of anhydride moieties allows for a number of biomolecular functionalization strategies without toxic coupling agents [16]. This is demonstrated for the binding of laminin and chondroitin-6-sulphate to promote initial cell attatchment of immortalized, adult human corneal endothelial cells (HCEC). This cell type established by Bednarz et al. [17] and further characterized by Valtink et al. [18] was cultivated on maleic anhydride (MA) functionalized SRP substrates either with covalently bound or physisorbed proteins.

\section{Experimental}

\subsection{Materials and sample preparation}

For the experiments of this work two SRP materials were investigated (Figure 1): i) Poly(vinyl methyl ether) (TCI Europe, Zwijndrecht, Belgium) and ii) a mixture of PVME and the alternating copolymer of PVME and maleic anhydride (Sigma-Aldrich, Munich, Germany) with a copolymer content of $10 \% \mathrm{wt} / \mathrm{wt}$ (PVME-MA). Electron beam irradiation was carried out with the low energy electron facility ADU (Advanced Electron Beams, Wilmington, USA) under nitrogen atmosphere at room temperature. The electron energy of $150 \mathrm{keV}$ corresponds to a maximum penetration depth of about $200 \mu \mathrm{m}$ in polymeric materials.
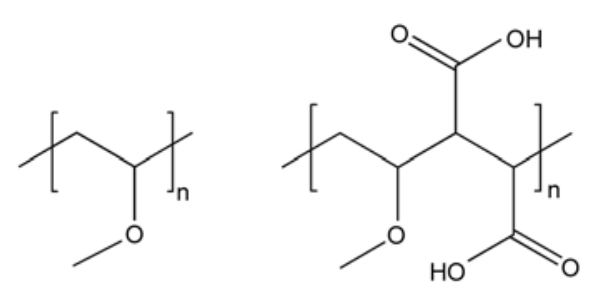

Figure 1. Poly(vinyl methyl ether) and poly(vinyl methyl ether-co-maleic acid)
To study the effect of electron beam cross-linking on the structure of the SRP, thin films of about $70 \mathrm{~nm}$ were applied by spin coating (solution $2 \% \mathrm{wt} / \mathrm{wt}$ in methanol, $2000 \mathrm{rpm}, 1500 \mathrm{rpm} / \mathrm{s}, 30 \mathrm{~s}$ ) onto internal reflection elements for ATR-FTIR spectroscopy. Subsequently, the samples were irradiated with an absorbed dose of $260 \mathrm{kGy}$ in 11 steps in order to reduce temperature increase during electron treatment.

To allow in situ investigations of the swelling behavior of immobilized SRP layers by spectroscopic ellipsometry, polystyrene coated silicon wafers were used as substrates for the experiments of this work. For that purpose polystyrene coatings (PS, type $148 \mathrm{H}, \mathrm{BASF}$, Ludwigshafen, Germany) of about $30 \mathrm{~nm}$ thickness were applied by spin coating onto silicon wafers $15 \times 20 \mathrm{~mm}^{2}$ (solution $1 \% \mathrm{wt} / \mathrm{wt}$ in toluene, $2000 \mathrm{rpm}, 1500 \mathrm{rpm} / \mathrm{s}, 30 \mathrm{~s}$ ). PS surfaces were treated in air plasma to obtain an appropriate wetting behavior (Harrick Plasma Cleaner PDC 002, $1 \mathrm{~min}$ ). Subsequently, a SRP layer was prepared by spin coating (solution $2 \% \mathrm{wt} / \mathrm{wt}$ in methanol, $2000 \mathrm{rpm}, 1500 \mathrm{rpm} / \mathrm{s}, 30 \mathrm{~s}$ ) on top of the PS film. The samples were irradiated with different absorbed doses (118-780 kGy) in steps of $23.6 \mathrm{kGy}$ in order to reduce the temperature increase during electron treatment. Finally, they were rinsed in water to remove unbound material. For the cell culture experiments cover slips (Menzel-Gläser, Braunschweig, Germany) with a diameter of $20 \mathrm{~mm}$ were used instead of silicon wafers.

\subsection{Spectroscopic ellipsometry}

Ellipsometric measurements were performed using a variable angle spectroscopic ellipsometer $\mathrm{M}$ 2000VI (J. A. Woollam Co., Inc., Lincoln, USA). It is a Diode Array Rotating Compensator Ellipsometer $\left(\mathrm{DARCE}^{\mathrm{TM}}\right)$ in polarizer compensator sample analyzer configuration equipped with a computercontrolled goniometer and a horizontally mounted sample stage. The light source is a $50 \mathrm{~W}$ mercury lamp. For a given angle of incidence, the M-2000VI measures 500 wavelengths simultaneously covering the spectral range from $370-1700 \mathrm{~nm}$. Accurate measurements over the full $\Delta$ and $\Psi$ range were acquired $\left(\Delta=0^{\circ}-360^{\circ} ; \Psi=0^{\circ}-90^{\circ}\right)$.

In case of dry samples, values from three angles of incidence, 65,70 and $75^{\circ}$ were acquired. To investigate swollen hydrogel layers, a liquid media cell 


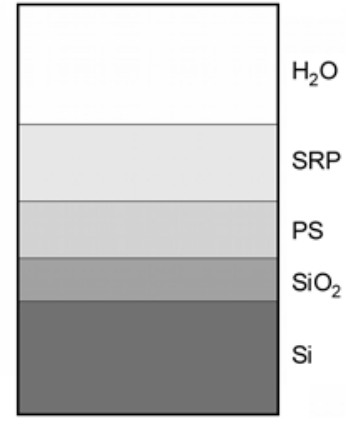

Figure 2. Multilayer model for ellipsometric investigations

(angle of incidence $68^{\circ}$ ) with de-ionized water $(\mathrm{pH}$ 6.5) was used. For the variation of temperature with a rate of $1 \mathrm{~K} \cdot \mathrm{min}^{-1}$, a computer-controlled heating device for the liquid media cell was used.

To calculate the thickness and the optical properties of the polymer films under investigation, fit procedures based on Cauchy multilayer models were applied to the the ellipsometric data (Figure 2). An effective medium approximation was used in case of swollen hydrogel layers.

The swelling degree was calculated as $Q=d_{\mathrm{T}} / d_{\mathrm{dry}}$, were $d_{\mathrm{T}}$ corresponds to the swollen film thickness at a given temperature and $d_{\text {dry }}$ to the dry film thickness.

\subsection{Infrared spectroscopy}

FTIR-ATR spectra were obtained with a Vector 22 FTIR spectrometer (Bruker, Ettlingen, Germany) using trapezoidal shaped internal reflection elements (IRE) made of chalcogenide glass IRG100 [19] with $45^{\circ}$ incident angle and 17 reflections (9 effective reflections on the coated side). Sample spectrum and background spectrum were acquired with the coated IRE and the clean IRE respectively. For the film thickness used in this work, the thinfilm case of ATR spectroscopy applies [20]. In this case the film thickness limits the sampling depth, i.e., there is no variation of the sampling depth with wavelength. Consequently, absorbance units are given instead of ATR units.

\subsection{Cell cultivation}

Sterilization of the SRP-coated cover slips was performed by incubating for $24 \mathrm{~h}$ in $0.02 \% \operatorname{ProClin}^{\circledR}$ 300 Preservative (Supleco, Sigma-Aldrich, Munich, Germany) diluted in phosphate buffered saline (PBS, w/o $\mathrm{Mg}^{2+}, \mathrm{Ca}^{2+}$ ) at room temperature, followed by a rinsing step and incubation in PBS (w/o
$\mathrm{Mg}^{2+}, \mathrm{Ca}^{2+}$ ) for $24 \mathrm{~h}$. MA containing surfaces were either tempered under sterile conditions overnight at $90^{\circ} \mathrm{C}$ to activate the MA moieties witch allows the covalent binding of proteins. Control surfaces were not tempered which allows only physisorptive protein binding. The samples were incubated for $2 \mathrm{~h}$ at $37^{\circ} \mathrm{C}$ with the protein mixture of $10 \mathrm{mg} / \mathrm{ml}$ laminin (Invitrogen, Karlsruhe, Germany) and $10 \mathrm{mg} / \mathrm{ml}$ chondroitin-6-sulphate (Sigma-Aldrich, Munich, Germany). Then samples were rinsed with prewarmed PBS (w/o $\mathrm{Mg}^{2+}, \mathrm{Ca}^{2+}$ ) and conditioned with the growth medium for $30 \mathrm{~min}$. Finally, cells were seeded at a density of 5000 cells per $\mathrm{cm}^{2}$.

They were grown serum-supplemented in F99 $9_{\text {HCEC }}$ [Nutrient Mixture Ham's F12/Medium 199 (Biochrom AG, Berlin, Germany) with 5\% FCS (Invitrogen), $20 \mathrm{mg} / \mathrm{ml}$ ascorbic acid (Sigma-Aldrich), $10 \mathrm{ng} / \mathrm{ml}$ human recombinant FGF-2 (Invitrogen), $20 \mathrm{mg} / \mathrm{ml}$ human recombinant insulin (SigmaAldrich) and antibiotics $(2.5 \mathrm{mg} / \mathrm{ml}$ amphotericin B and $50 \mathrm{mg} / \mathrm{ml}$ gentamycin; Biochrom)] at $37^{\circ} \mathrm{C}$ and $5 \% \mathrm{CO}_{2}$.

\section{Results and discussion}

Figure 3 shows the efficiency of PVME immobilization as a function of the absorbed dose. At an absorbed dose of at least $500 \mathrm{kGy}$ the material of a pre-deposited PVME thin film is fully immobilized on a polystyrene carrier. For lower dose values a part of the pre-deposited and electron beam irradiated PVME is removed when immersed in distilled water. However, the known fraction according to

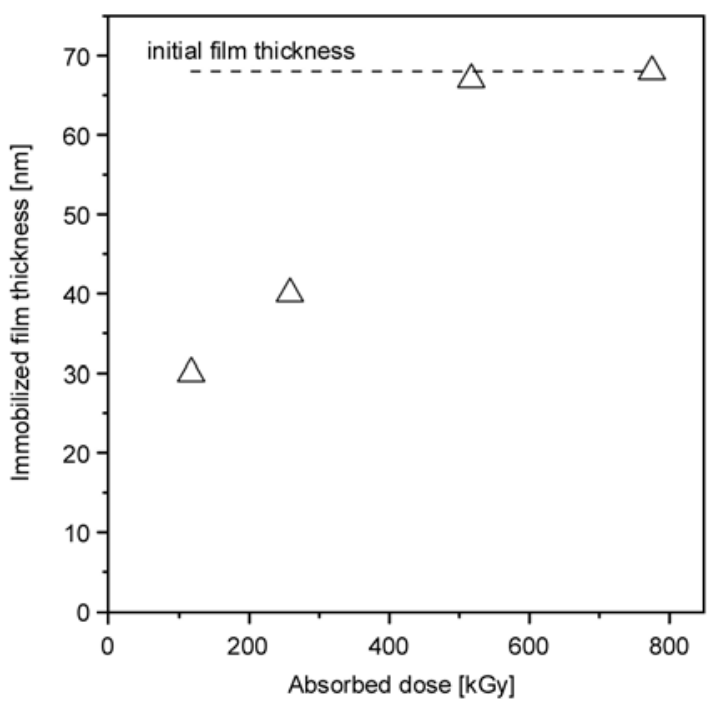

Figure 3. Efficiency of PVME immobilization on polystyrene as a function of absorbed dose 


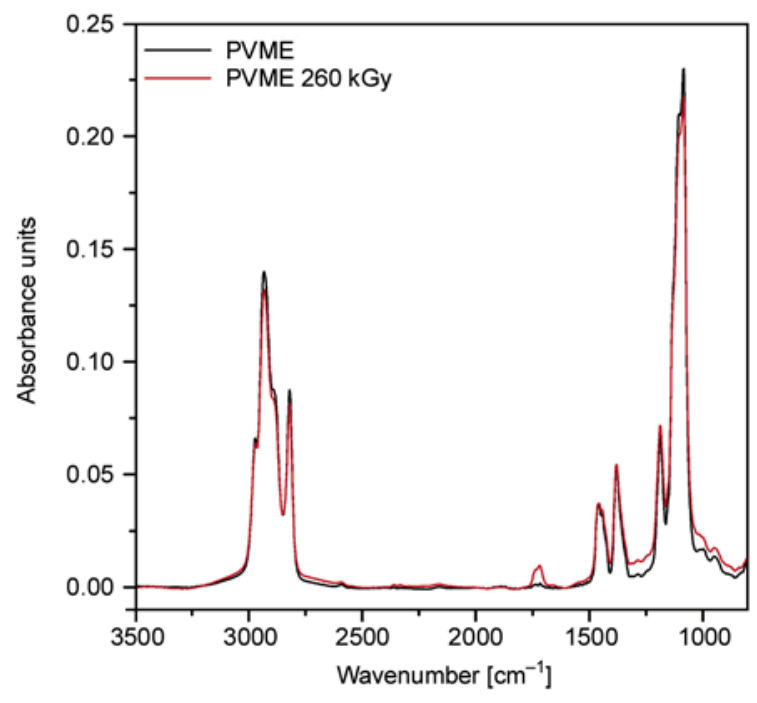

Figure 4. Infrared spectra of non-irradiated and irradiated PVME

Figure 3 allows to prepare a coating with a given thickness of the immobilized material.

The structure retention of the PVME upon electron beam immobilization was proven by infrared spectroscopy. Figure 4 compares the spectra of non-irradiated and irradiated PVME. The only significant difference is the appearance of a $\mathrm{C}=\mathrm{O}$ stretching band at $1720 \mathrm{~cm}^{-1}$ which is attributed to oxidative degradation of PVME due to post reaction of persistent radicals formed as a result of the irradiation. Figure 5 illustrates the temperature dependent swelling behavior of immobilized PVME thin films as determined by spectroscopic ellipsometry. Irrespective of the applied dose, the material shows a thermo-responsive effect with a critical temperature

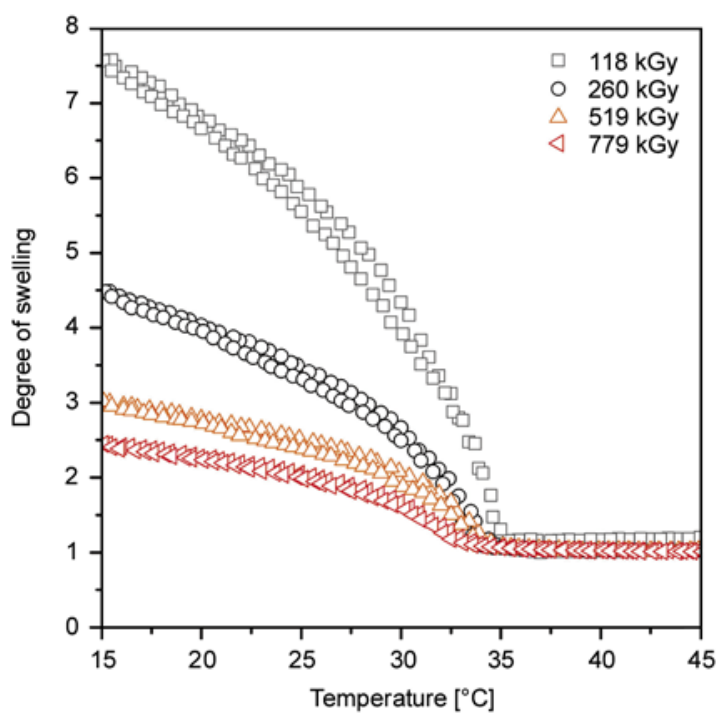

Figure 5. Temperature dependent swelling behavior of immobilized PVME thin fims during heating and cooling

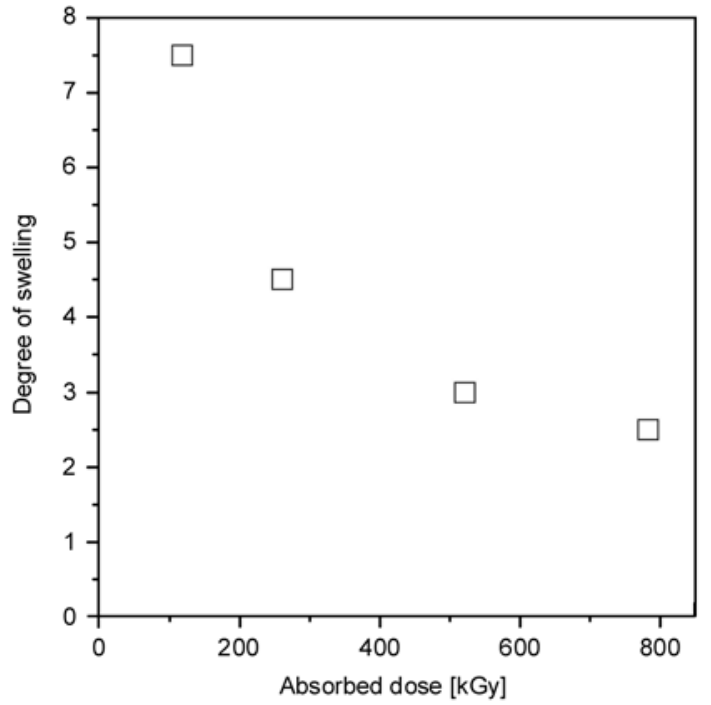

Figure 6. Degree of swelling of immobilized PVME thin films at $15^{\circ} \mathrm{C}$ depending on the absorbed dose

of about $34^{\circ} \mathrm{C}$. While all films are fully collapsed above this threshold, a dose dependent degree of swelling is found when cooling down the system. For a lower absorbed dose, i.e. for a lower degree of cross-linking of the hydrogel, the degree of swelling increases (Figure 6). Furthermore, the onset of the swelling gets sharper and more pronounced while the gradient of the swelling curve slightly below the critical temperature increases significantly. The temperature dependent swelling is fully reversible for all cases investigated. The process does not show a pronounced hysteresis, i.e. heating and cooling curves are virtually the same. The water is fully expelled in the collapsed state (degree of swelling = 1). Both facts set apart PVME from PNiPAAm and NiPAAm containing copolymers as investigated in previous studies $[4,21]$. The influence of the cell culture medium to the transition behavior is expected to lower the transition temperature by 1-2 K [22]. The shown behavior of PVME thin films on polystyrene substrates corroborate the results of Hegewald et al. [23] obtained for thicker layers of PVME directly prepared on silicon oxide surfaces.

To allow for biomolecular functionalization of the thermo-responsive coating described so far, a mixture of PVME and the copolymer of PVME and maleic acid (PVME-MA) was immobilized and characterized in the same way. Figure 7 illustrates, that the thermo-responsive behavior of the system is largely preserved when adding $10 \% \mathrm{wt} / \mathrm{wt}$ of the functional copolymer. The acid groups in the immobilized film can be transformed into anhydride moi- 


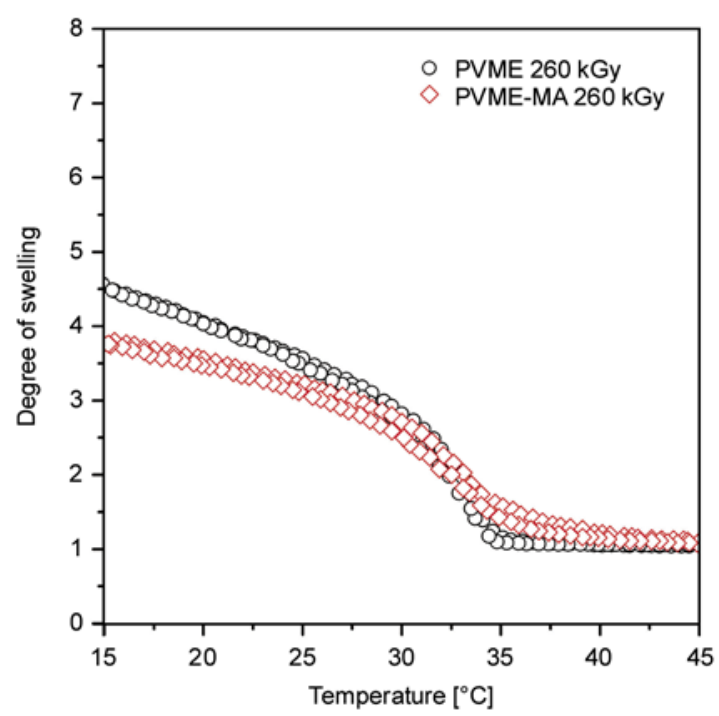

Figure 7. Changes in the temperature dependent swelling behavior of immobilized PVME after adding $10 \% \mathrm{wt} / \mathrm{wt}$ PVME-MA<smiles>COC(CC(C)(C)C)C(OC)C(C(=O)O)C(C(=O)O)C(C)(C)C</smiles>

Figure 8. Example of the anhydride formation in the added copolymer

eties when stored at $120^{\circ} \mathrm{C}$ for $2 \mathrm{~h}$ (Figure 8). This was proven by infrared spectroscopy (Figure 9). The band at $1725 \mathrm{~cm}^{-1}(\mathrm{C}=\mathrm{O}$ stretching in $\mathrm{COOH})$ is gradually disappearing and replaced by two bands at 1775 and $1860 \mathrm{~cm}^{-1}(\mathrm{C}=\mathrm{O}$ stretching of cyclic anhydrides) [24].

The restored anhydride moieties are now available for further biomolecular modifications with extracellular matrix proteins, peptides or amino end group functionalized polyethylene glycols. This allows to precisely adjust the physicochemical characteristic

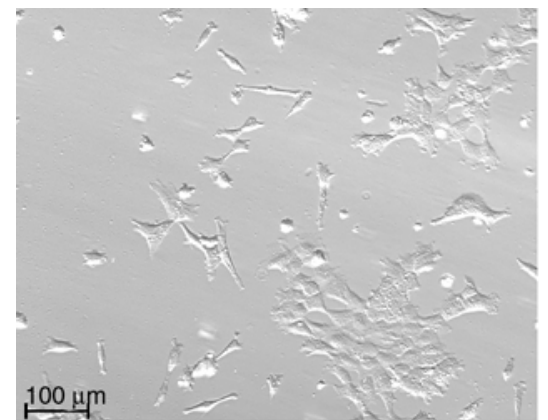

a)

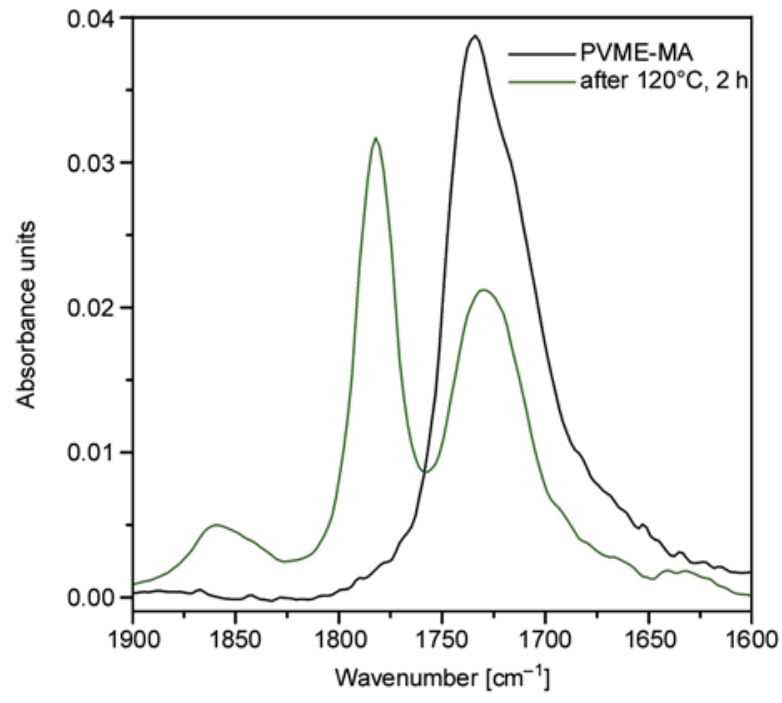

Figure 9. Infrared spectra of immobilized PVME-MA before and after storage at $120^{\circ} \mathrm{C}$ for $2 \mathrm{~h}$

of the surface for enhanced adhesion and proliferation or accelerated detachment of cultured cells. The enhanced adhesion after the covalent decoration is demonstrated in Figure 10. It shows the adhesion and growth of HCEC after two days of cultivation on a blend SRP layer of PVME and $10 \% \mathrm{wt} / \mathrm{wt}$ PVME-MA (33 nm dry thickness, $260 \mathrm{kGy}$ absorbed dose) with physisorptive and covalent binding of laminin and chondroitin-6-sulfate.

\section{Conclusions}

Thin films of the thermo-responsive polymer poly (vinyl methyl ether) were immobilized on polystyrene, the most common material for cell culture carriers. The high affinity to electron beam crosslinking allows to tailor the properties of the PVME films easily. Stable coatings with a dry thickness up to $100 \mu \mathrm{m}$ can be achieved using an electron energy of $150 \mathrm{keV}$. The swelling behavior of the immobilized PVME films can be adjusted by variation of

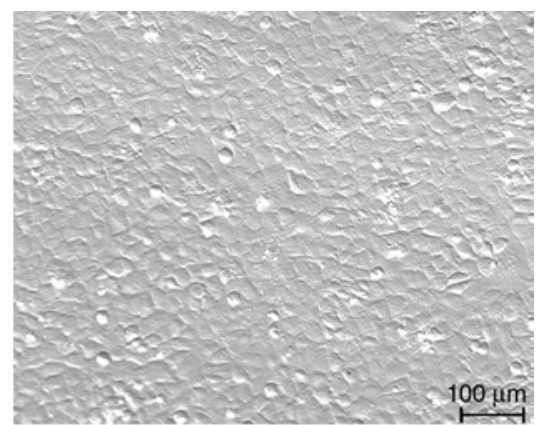

b)

Figure 10. Adhesion and growth of HCEC after two days of cultivation on a blend SRP layer of PVME and 10\% wt/wt PVME-MA (33 nm dry thickness, $260 \mathrm{kGy}$ absorbed dose) with physisorptive (a) and covalent binding (b) of laminin and chondroitin-6-sulfate 
the absorbed dose. Systems with a critical temperature of $34^{\circ} \mathrm{C}$ and a different cross-linking corresponding to a degree of swelling between 2.5 and 7.7 were demonstrated. The variability of the mechanical properties of the thermo responsive coating is complemented with a chemical functionalization by introducing a copolymer carrying reactive anhydride sites. This approach combines the concept of thermo responsive cell culture carriers with an anhydride-based platform technology for biomolecular modification.

\section{Acknowledgements}

This work was supported by the European Regional Development Fund, project 4212/09 15. The authors thank Roland Schulze (IPF Dresden) for ellipsometry measurements and Michael Spaethe (IPF Dresden) for operating the electron beam irradiation setup.

\section{References}

[1] de las Heras Alarcón C., Pennadam S., Alexander C.: Stimuli responsive polymers for biomedical applications. Chemical Society Reviews, 34, 276-285 (2005). DOI: $10.1039 / \mathrm{b} 406727 \mathrm{~d}$

[2] Mendes P. M.: Stimuli-responsive surfaces for bioapplications. Chemical Society Reviews, 37, 25122529 (2008).

DOI: $10.1039 / \mathrm{b} 714635 \mathrm{n}$

[3] Yamato M., Akiyama Y., Kobayashi J., Yang J., Kikuchi A., Okano T.: Temperature-responsive cell culture surfaces for regenerative medicine with cell sheet engineering. Progress in Polymer Science, 32, 11231133 (2007).

DOI: $10.1016 /$ j.progpolymsci.2007.06.002

[4] Schmaljohann D., Beyerlein D., Nitschke M., Werner C.: Thermo-reversible swelling of thin hydrogel films immobilized by low-pressure plasma. Langmuir, 20, 10107-10114 (2004).

DOI: $10.1021 / 1 \mathrm{a} 034653 \mathrm{f}$

[5] Da Silva R. M. P., Mano J. F., Reis R. L.: Smart thermoresponsive coatings and surfaces for tissue engineering: Switching cell-material boundaries. Trends in Biotechnology, 25, 577-583 (2007). DOI: $10.1016 /$ j.tibtech.2007.08.014

[6] Rzaev Z. M. O., Dinçer S., Pişkin E.: Functional copolymers of $\mathrm{N}$-isopropylacrylamide for bioengineering applications. Progress in Polymer Science, 32, 534-595 (2007).

DOI: 10.1016/j.progpolymsci.2007.01.006

[7] Schild H. G.: Poly( $N$-isopropylacrylamide): Experiment, theory and application. Progress in Polymer Science, 17, 163-249 (1992).

DOI: 10.1016/0079-6700(92)90023-R
[8] Cooperstein M. A., Canavan H. E.: Biological cell detachment from poly( $N$-isopropyl acrylamide $)$ and its applications. Langmuir, 26, 7695-7707 (2010). DOI: $10.1021 / 1 \mathrm{a902587p}$

[9] Hegewald J., Schmidt T., Gohs U., Günther M., Reichelt R., Stiller B., Arndt K-F.: Electron beam irradiation of poly(vinyl methyl ether) films: 1 . Synthesis and film topography. Langmuir, 21, 6073-6080 (2005). DOI: 10.1021/la0502589

[10] Schäfer-Soenen H., Moerkerke R., Berghmans H., Koningsveld R., Dušek K., Šolc K.: Zero and off-zero critical concentrations in systems containing polydisperse polymers with very high molar masses. 2 . The system water-poly(vinyl methyl ether). Macromolecules, 30, 410-416 (1997).

DOI: $10.1021 / \mathrm{ma9601140}$

[11] Karakeçili A. G., Satrianob C., Gümüşderelioğlu M., Marletta G.: Thermoresponsive and bioactive poly (vinyl ether)-based hydrogels synthesized by radiation copolymerization and photochemical immobilization. Radiation Physics and Chemistry, 77, 154-161 (2008). DOI: $10.1016 /$ j.radphyschem.2007.04.014

[12] Janik I., Kasprzak E., Al-Zier A., Rosiak J. M.: Radiation crosslinking and scission parameters for poly (vinyl methyl ether) in aqueous solution. Nuclear Instruments and Methods in Physics Research Section B: Beam Interactions with Materials and Atoms, 208, 374-379 (2003). DOI: 10.1016/S0168-583X(03)00897-8

[13] McHerron D. C., Wilkes G. L.: Electron beam irradiation of polystyrene-poly(vinyl methyl ether) blends. Polymer, 34, 3976-3985 (1993).

DOI: 10.1016/0032-3861(93)90657-V

[14] Hatakeyama H., Kikuchi A., Yamato M., Okano T.: Bio-functionalized thermoresponsive interfaces facilitating cell adhesion and proliferation. Biomaterials, 27, 5069-5078 (2006).

DOI: 10.1016/j.biomaterials.2006.05.019

[15] Kwon O. H., Kikuchi A., Yamato M., Okano T.: Accelerated cell sheet recovery by co-grafting of PEG with PIPAAm onto porous cell culture membranes. Biomaterials, 24, 1223-1232 (2003). DOI: 10.1016/S0142-9612(02)00469-6

[16] Pompe T., Zschoche S., Herold N., Salchert K., Gouzy M-F., Sperling C., Werner C.: Maleic anhydride copolymers - A versatile platform for molecular biosurface engineering. Biomacromolecules, 4, 1072-1079 (2003). DOI: $10.1021 / \mathrm{bm} 034071 \mathrm{c}$

[17] Bednarz J., Teifel M., Friedl P., Engelmann K.: Immortalization of human corneal endothelial cells using electroporation protocol optimized for human corneal endothelial and human retinal pigment epithelial cells. Acta Ophthalmologica Scandinavica, 78, 130-136 (2000).

DOI: $10.1034 / \mathrm{j} .1600-0420.2000 .078002130 . \mathrm{x}$ 
[18] Valtink M., Gruschwitz R., Funk R. H. W., Engelmann K.: Two clonal cell lines of immortalized human corneal endothelial cells show either differentiated or precursor cell characteristics. Cells Tissues Organs, 187, 286-294 (2008).

DOI: $10.1159 / 000113406$

[19] Kloceck P.: Handbook of infrared optical materials. Marcel Dekker, New York (1991).

[20] Harrick N. J.: Internal reflection spectroscopy. Wiley, New York (1975).

[21] Nitschke M., Götze T., Gramm S., Werner C.: Detachment of human endothelial cell sheets from thermoresponsive poly(NiPAAm-co-DEGMA) carriers. Express Polymer Letters, 1, 660-666 (2007).

DOI: $10.3144 /$ expresspolymlett.2007.90
[22] Schmaljohann D., Oswald J., Jørgensen B., Nitschke M., Beyerlein D., Werner C.: Thermo-responsive PNiPAAm- $g$-PEG films for controlled cell detachment. Biomacromolecules, 4, 1733-1739 (2003). DOI: $10.1021 / \mathrm{bm} 034160 \mathrm{p}$

[23] Hegewald J., Schmidt T., Eichhorn K-J., Kretschmer K., Kuckling D., Arndt K-F.: Electron beam irradiation of poly(vinyl methyl ether) films. 2. Temperaturedependent swelling behavior. Langmuir, 22, 51525159 (2006).

DOI: $10.1021 / \mathrm{la} 053461 \mathrm{c}$

[24] Lin-Vien D., Colthub N. B., Fately W. G., Grasseli J. G.: The handbook of infrared and raman characteristic frequencies of organic molecules. Academic Press, London (1991). 